\title{
MULTIFUNCIONALIDADE DE AGRICULTURA FAMILIAR NO DISTRITO
} DE CHIBUTO

\section{Multifunctionality of Family Farm in Chibuto District}

\author{
Mussá Abdul Remane \\ Universidade Pedagógica, Moçambique \\ mareman2@gmail.com
}

Artigo recebido em 30/08/2015 e aceito para publicação em 17/10/2015

DOI: $10.12957 /$ tamoios.2015.20807

Resumo

\begin{abstract}
Analyzes in this paper the performance of multiple family farming functions of Chibuto district, with the sample areas, the administrative posts of Malehice, Chibuto host and Chaimite. Wanted describe the multifunctional aspects of agriculture, highlighting the socio-economic reproduction, food security, the maintenance of the social and cultural fabric and the preservation of natural resources and rural landscape. The factors that influence the performance of these functions are explained: territorial dynamics and collective projects. By applying the quantitative-quality method of approach, embodied by the observational procedure and the semi-structured interview techniques and direct observation, we seek to demonstrate that the performance of multiple functions of agriculture practiced by the family sector is expressed by the low yield family currency, high unemployment, reduced food security, loss of habits and family customs and community, low use of soil conservation techniques. Some factors that explain this scenario are: the level of association of family members and the public policies that have been reported with less convergence. Thus, the concept of multifunctionality of family farming in the district should be taken into account in all policy-making contexts and strategies aimed at sustainable rural development.
\end{abstract}

Palavras-chave: Multifuncionalidade, Agricultura Familiar, Território,

Desenvolvimento Territorial

Keywords: Multifunctionality, Family Agriculture, Land, Territorial Development 


\section{INTRODUÇÃO}

O presente artigo tem como tema de estudo, a multifuncionalidade de agricultura familiar no distrito de chibuto, tendo como áreas amostrais os Postos Administrativos de Malehice, Chibuto-Sede e Chaimite. Visa, de uma forma geral, analisar o desempenho das múltiplas funções atribuídas à Agricultura Familiar, desde a óptica das dinâmicas de reprodução socioeconómica das famílias até a preservação dos recursos naturais e paisagem rural do Distrito de Chibuto.

A noção da multifuncionalidade é tomada como um novo olhar sobre a agricultura familiar, que permite analisar a interacção entre famílias rurais e territórios na dinâmica da reprodução social, considerando os modos de vida das famílias na sua integridade e não apenas seus componentes económicos (CAZELLA, et al, 2009). Ela incorpora a provisão, por parte desses agricultores, de bens públicos relacionados com o meio ambiente, segurança alimentar e o património cultural.

Assim, a multifuncionalidade da agricultura familiar inclui quatro funções fundamentais que reflectem aspectos de cada contexto sócio-espacial ou territorial, tal como reportam os estudos realizados por vários pesquisadores incluindo Carveiro \& Maluf (2003) citado por Cazella, et al (2009):

a) Reprodução socioeconómica das famílias rurais que consiste na geração de trabalho e da renda que permita as famílias rurais se manterem no campo em condições dignas, função proeminente num contexto de elevado desemprego e de baixa renda para amplos segmentos da população;

b) Promoção da segurança alimentar das próprias famílias rurais e da sociedade, no sentido da disponibilidade e acesso aos alimentos, e a qualidade dos mesmos;

c) Manutenção do tecido social e cultural - esta função explica-se pelo facto da agricultura figurar-se ainda como o principal factor definidor da identidade e a condição da inserção social das famílias rurais;

d) Preservação dos recursos naturais e da paisagem rural - esta função não é tão notável e configura-se como a mais difícil que a agricultura familiar desempenha, em virtude de se verificarem conflitos generalizados entre os objectivos da preservação dos recursos naturais e a prática dessa agricultura, relacionados com o uso sustentável dos recursos naturais e com o confronto entre as práticas agrícolas e aspectos da legislação ambiental. 
Os territórios são usualmente considerados unidades privilegiadas de expressão de multifuncionalidade da agricultura a serem tomadas em conta na definição das políticas públicas. Cazella, et al (2009) consideram quatro concepções que permeiam a relação entre a multifuncionalidade de agricultura familiar e o enfoque territorial, a destacar:

- Território como lugar de expressão e de tratamento de externalidades de agricultura: Para o caso da multifuncionalidade de agricultura, o enfoque centrase nas externalidades ligadas às actividades agrícolas, pecuárias, pesqueiras e florestais, e o território figura-se como o espaço de aplicação dos instrumentos de política pública;

- Território como resultado de projectos colectivos voltados para a construção de recursos específicos e discriminantes: A multifuncionalidade deixa de ser uma característica de agricultura para se transformar em uma característica construída do território.

- Território como resultado de projectos colectivos convergentes não exclusivamente económicos: $\mathrm{O}$ território pode ser condicionado pelo meio ambiente ou pela estrutura de povoamento;

- Território como componente fundamental de sociedades territoriais: A multifuncionalidade da agricultura expressa-se nesta, mediante a diversidade das formas de intercâmbio e reciprocidade em torno dos produtos agro-pecuários, do acesso aos recursos naturais e das relações de trabalho.

Chibuto compõe um dos conjuntos de distritos que fica localizado no Sudeste da Província de Gaza, próximo da confluência dos Rios Limpopo e Changane, limitando-se a Este com os distritos de Manjacaze e Panda; a Norte com o distrito de Chigubo; a Oeste com os distritos de Guijá e Chókwe; e a Sul com os distritos de Xai-Xai e BileneMacia.

De acordo com o Terceiro Recenseamento Geral da População e Habitação (III RGPH) de 2007, a população do distrito de Chibuto é estimada de cerca de 191.682 habitantes dos quais cerca de 44,3\% são Homens e 55,7\% Mulheres, cuja densidade populacional é de $29.3 \mathrm{hab} / \mathrm{km}^{2}$ e o número de agregados familiares é de 40.236 .

A cidade de Chibuto (Sede do distrito) e Malehice constituem os postos administrativos mais habitados cobrindo cerca de $33 \%$ e $29 \%$ da população total, respectivamente [Instituto Nacional de Estatística (INE), 2010]. 
Desta forma, em torno do artigo procura-se analisar o desempenho das múltiplas funções atribuídas a agricultura familiar no Distrito de Chibuto.

\section{PROCEDIMENTOS METODOLÓGICOS}

Sob o ponto de vista da forma de abordagem do problema, a presente pesquisa embasou-se na abordagem quanti-qualitativa, na medida em que traduziu em números os dados recolhidos recorrendo à análise descritiva e relacionou-os com os seus atributos ao interpretá-los. A discussão acerca das abordagens da multifuncionalidade de agricultura praticada pelas famílias rurais do distrito de Chibuto foi possível recorrendo à revisão de vários materiais publicados como livros, artigos científicos bem como recursos virtuais como material disponível na internet.

O processo de recolha de dados consistiu na deslocação ao distrito de Chibuto, concretamente aos Postos Administrativos referidos anteriormente, no período entre Agosto e Novembro de 2013, de forma a solicitar informação diante das famílias rurais praticantes de agricultura e dos membros de algumas associações e instituições públicas e privadas, a respeito das múltiplas funções de agricultura praticada pelo sector familiar e dos factores que afectam o seu desempenho. Deste modo, foram usados o método observacional e às técnicas de entrevista e observação directa.

O método observacional permitiu, de forma geral, a observação e a recolha de informação sobre as múltiplas funções de agricultura, servindo-se da entrevista e observação directa. A entrevista (semi-estruturada) realizada no terreno foi dirigida aos vários integrantes dos projectos colectivos (membros das instituições publicas e das associações dos agricultores), aos membros dos agregados familiares (como principal alvo), especialmente para as famílias camponesas, e aos membros integrantes projectos privados ou iniciativas privadas.

A observação directa como técnica, foi usada nesta pesquisa para registar dados referentes à paisagem rural onde as famílias e as empresas produzem as suas culturas bem como os locais da sua habitação e do desenvolvimento de outras actividades fora da agricultura. Como amostra, foram seleccionados os Postos Administrativos de Malehice, Chaimite e Chibuto-Sede, donde se determinou com base na fórmula abaixo idealizada por Mulenga (2010), o tamanho de amostra de 589 agregados familiares. Porém, não foi possível cobrir este tamanho amostral, dada a dificuldade financeira, em 
relação ao tempo e espaço, que o autor enfrentou. Assim, foram entrevistados 301 agregados familiares distribuídos em três Postos Administrativo (100 agregados para Malehice, 100 para Chaimite e 101 para Chibuto-Sede).

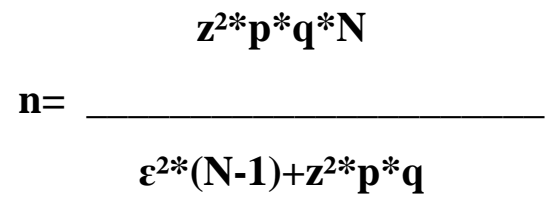

Onde,

$\mathbf{N}$ = número total dos agregados familiares -31366 ;

$\mathbf{n}=$ tamanho de amostra;

$\mathbf{z}=$ valor crítico, obtido a partir de um nível de confiança de 95\%;

$\mathbf{p}=$ proporção dos factores determinantes de múltiplas funções de agricultura familiar $50 \%$;

$\mathbf{q}=1$-p, proporção de característica não pesquisada na população $-50 \%$; $\varepsilon=$ erro de estimação de $4 \%$.

Para a análise e interpretação dos dados recolhidos foram usadas as tabelas de frequências para organizar e resumir o número de vezes que os valores de cada variável ocorreram, para além dos gráficos que fornecem uma visão resumida dos dados e mostram a tendência ou o comportamento das variáveis. Para tal, recorreu-se ao pacote estatístico SPSS versão 18.0, ideal para os dados relativos às questões sociais.

A interpretação dos dados foi feita baseando-se no modelo teórico sobre território e desenvolvimento territorial estabelecido por CAZELLA, et al (2009) e complementando com outros conhecimentos teóricos previamente adquiridos.

\section{RESULTADOS}

\section{Aspectos Multifuncionais de Agricultura Familiar no Distrito de Chibuto}

\section{Reprodução Socioeconómica das Famílias}

A reprodução socioeconómica das famílias diz respeito, segundo Cazella et al (2009), à geração de trabalho e de renda que permite as famílias rurais se manterem no campo em condições dignas. De entre várias características, o rendimento monetário e a permanência dos membros da família e da comunidade permitem explicar a função de 
reprodução socioeconómica das famílias rurais do Distrito de Chibuto desempenhada pela agricultura.

No que tange ao rendimento monetário do $\mathrm{AF}$, o gráfico 1 traz melhores evidências do nível do rendimento das famílias nos três PA’s. Pode se notar, através do gráfico, que em termos monetários, maior parte dos agregados familiares não dispõe de nenhum rendimento, tornando evidente que não são assalariados.

A tabela 1 alude a variável sobre a permanência da família na comunidade. Neste contexto, muitos jovens não têm permanecido na comunidade, ou seja, têm saído com destino à Maputo e Africa do Sul motivados pela procura do emprego, visto que nas suas comunidades há falta de emprego, ou se existe não satisfaz a demanda.

Gráfico 1. Renda monetária do agregado familiar

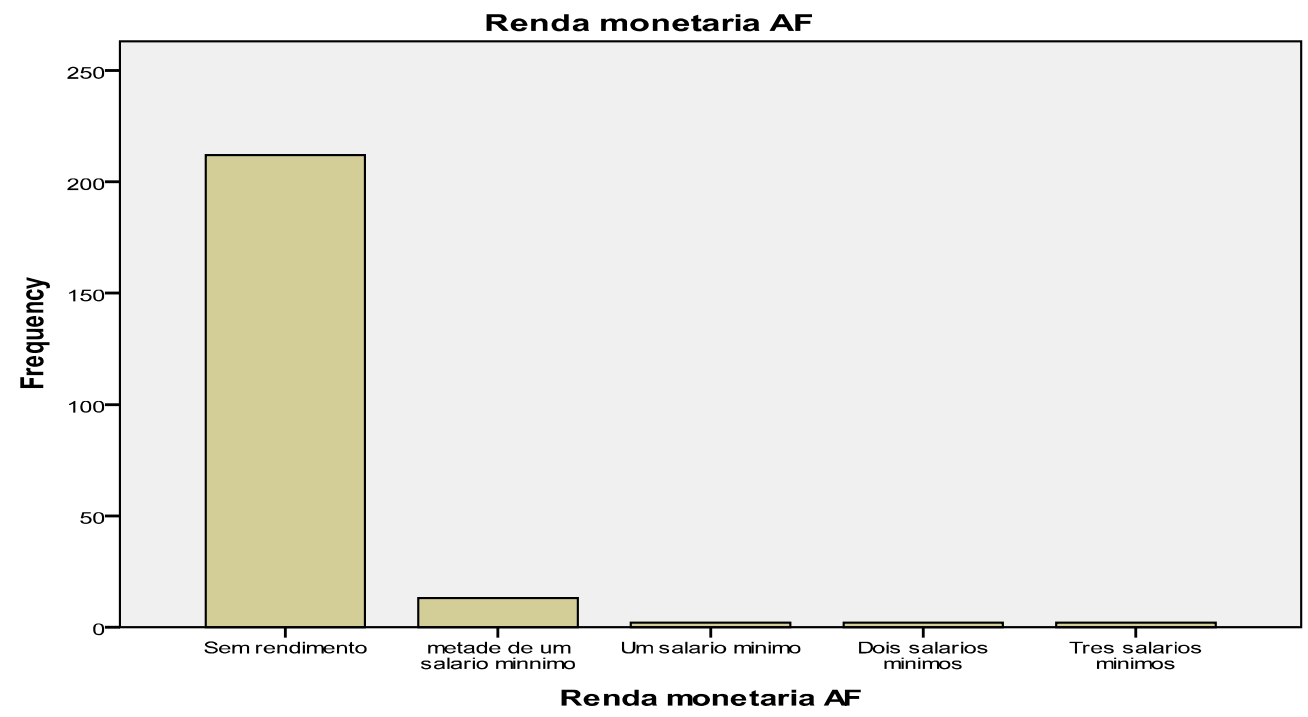

Fonte: Elaborado pelo Autor com base nos dados do campo, 2014

Tabela 1. Permanência da família na comunidade

$\begin{array}{lll}\text { Características } & \text { Frequência } & \text { Percentagem }\end{array}$

\begin{tabular}{ccc}
\hline $\begin{array}{c}\text { Permanência ou saída dos } \\
\text { jovens na comunidade }\end{array}$ & $(\mathrm{n}=300)$ & 100.0 \\
Sim & 290 & 96.7 \\
Não & 10 & 3.3 \\
& & \\
Destino dos jovens que saem & $(\mathrm{n}=301)$ & 100.0 \\
Maputo e Africa do Sul & 126 & 35.5 \\
Africa do Sul & 107 & 8.0 \\
Maputo & 24 &
\end{tabular}




\begin{tabular}{ccc}
\hline Motivo de Saida & $(\mathrm{n}=300)$ & 100 \\
Procura do emprego & 252 & 83.7 \\
Continuação dos estudos e & 18 & 6.0 \\
procura do emprego & 10 & 3.3 \\
Lar e procura do emprego & & \\
\hline
\end{tabular}

Fonte: Autor do trabalho com base nos dados recolhidos no campo, em 2103

\section{Segurança Alimentar das Famílias Rurais e da Sociedade}

O gráfico 2 ilustra o propósito da agricultura praticada pelos camponeses do distrito de Chibuto. Neste, a produção agrícola é destinada ao consumo familiar, pressupondo que não tendo um vínculo forte com o mercado.

Outas características que explicam a função de segurança alimentar são apresentadas na tabela 2. As famílias camponesas entrevistadas, na sua maioria, revelaram não ter garantia da segurança alimentar, dado que as suas famílias não estavam protegidas contra o risco de não ter alimentos suficientes para a alimentação.

\section{Manutenção do tecido social e cultural}

A manutenção do tecido social e cultural diz respeito, segundo Cazella et al, (2009:50), à contribuição da agricultura na definição da identidade e condição da inserção social das famílias rurais. A tabela 3 revela que a agricultura familiar no distrito não desempenha na sua plenitude a função de manutenção dos hábitos e costumes familiares, e a explicação deste cenário centra-se no desinteresse à sua prática e a dedicação dos membros da família à igreja.

\section{Preservação dos recursos naturais e paisagem rural}

A função de preservação dos recursos naturais e paisagem rural relaciona-se, tal como referem Cazella et al (2009), com o uso sustentável dos recursos naturais e reporta-se em muitos casos pelo confronto entre as práticas agrícolas, sobretudo as tradicionais, e os aspectos da legislação ambiental.

A tabela 4 explica melhor a função de agricultura familiar na preservação dos recursos naturais e paisagem rural, ao ilustrar que poucos agricultores usavam certas técnicas de conservação do solo. 
Numa outra vertente, foi também observado e registado o desmatamento e/ou queimada na área de cultivo, tal como ilustra a tabela 5. O desmatamento e/ou a queimada na área de cultivo é um fenómeno que tem-se observado nos PA's em estudo.

Gráfico 2. Destino da produção

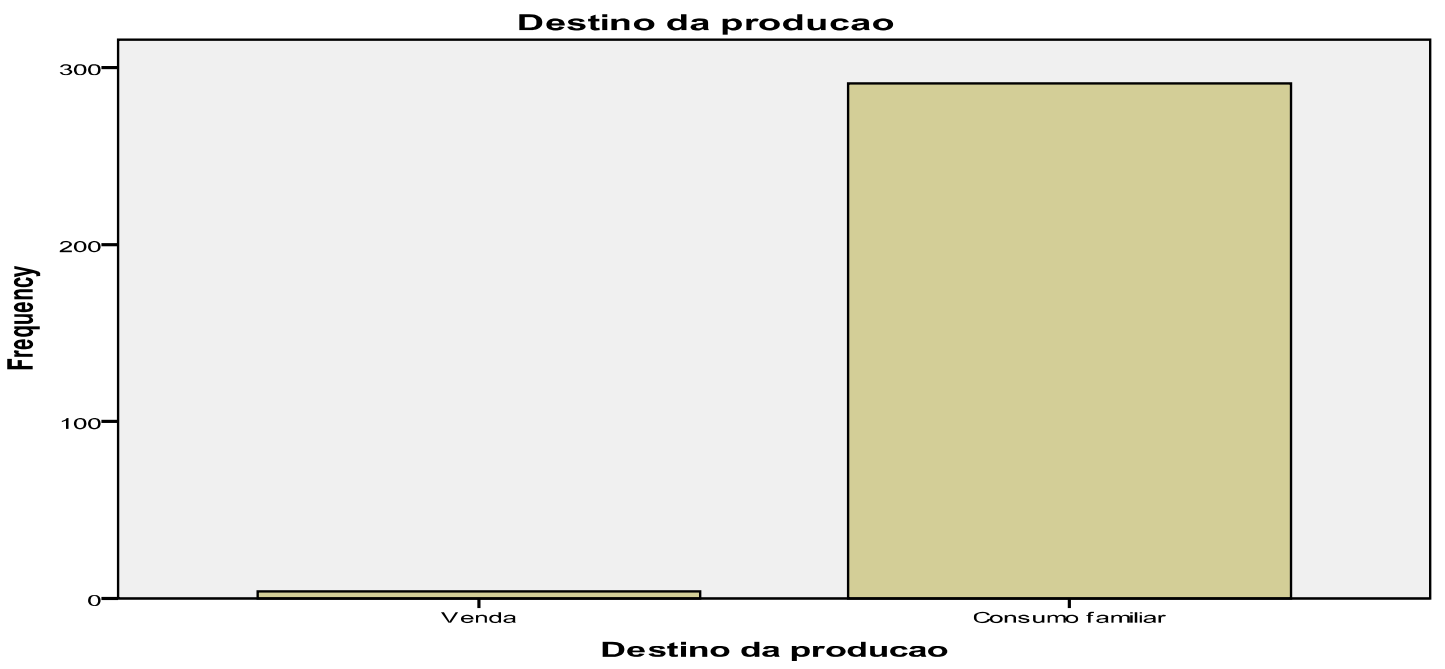

Fonte: Elaborado pelo Autor com base nos dados do campo, 2014

Tabela 2. Aspectos característicos da segurança alimentar

Características $\quad$ Frequência

Percentagem

$\begin{array}{ccc}\begin{array}{c}\text { Família protegida contra } \\ \text { o risco da insuficiência de } \\ \text { alimentos } \\ \text { Sim }\end{array} & (\mathrm{n}=300) & 100.0 \\ \text { Não } & 3 & 1 \\ \text { Não porque } & 297 & 99.0 \\ \begin{array}{c}\text { Insuficiência de condições } \\ \text { financeiras }\end{array} & (\mathrm{n}=300) & 100.0 \\ \begin{array}{c}\text { Falta de condições } \\ \text { financeiras }\end{array} & 230 & 76.4 \\ \begin{array}{c}\text { Insuficiência de produtos } \\ \text { alimentares }\end{array} & 46 & 15.3 \\ \end{array}$

Fonte: Autor do trabalho com base nos dados recolhidos no campo, em 2103 
Tabela 3. Manutenção dos hábitos e costumes do agregado familiar

$\begin{array}{lll}\text { Características } & \text { Frequência } & \text { Percentagem }\end{array}$

\begin{tabular}{ccc}
\hline $\begin{array}{c}\text { Hábitos e costumes do AF } \\
\text { que se mantem } \\
\text { Nehnum }\end{array}$ & $(\mathrm{n}=301)$ & 100.0 \\
Kuphalha & 172 & 57.1 \\
Produção de xintho para & 57 & 18.9 \\
kuphalha & 5 & 1.7 \\
Porque se mantem & & \\
Existem praticantes & $(\mathrm{n}=300)$ & 100.0 \\
Forma de lembrar-se dos & 48 & 15.9 \\
antepassados & 18 & 6.0 \\
Hábitos e costumes que & & \\
estão se perdendo no & $(\mathrm{n}=301)$ & 100.0 \\
agregado familiar & & \\
Todos & 142 & 47.2 \\
Sem ideia & 106 & 35.2 \\
Todos os outros & 19 & 6.3 \\
Porque se perdem & $(\mathrm{n}=301)$ & 100.0 \\
Ninguém mais se interessa & 173 & 57.5 \\
a sua prática, dedica-se a & & \\
igreja & & \\
\hline
\end{tabular}

Fonte: Autor do trabalho com base nos dados recolhidos no campo, em 2103

Tabela 4. Técnicas usadas na agricultura praticada pelas famílias rurais dos três PA's

\begin{tabular}{ccc}
\hline Características & Frequência & Percentagem \\
\hline $\begin{array}{c}\text { Uso de técnicas para a } \\
\text { conservação de solo }\end{array}$ & $(\mathrm{n}=295)$ & 100.0 \\
Sim & 41 & 13.9 \\
Não & 254 & 86.1 \\
& & \\
Técn. conservação de solo & $(\mathrm{n}=301)$ & 100.0 \\
Adubação orgânica & 8 & 2.7 \\
Uso de agrotóxicos & $(\mathrm{n}=295)$ & 100.0 \\
Sim & 8 & 2.7 \\
Não & 287 & 97.3 \\
& $(\mathrm{n}=301)$ & 100.0 \\
Agrotóxicos usados & 6 & 2.0 \\
Ureia &
\end{tabular}

Fonte: Autor do trabalho com base nos dados recolhidos no campo, em 2103 
Tabela 5. Desmatamento e/ou queimada na área do cultivo

\begin{tabular}{ccc} 
Características & Frequência & Percentagem \\
\hline $\begin{array}{c}\text { Desmatamento e/ou } \\
\text { ueimada na área a }\end{array}$ & $(\mathrm{n}=295)$ & 100.0 \\
cultivar & & \\
Sim & 249 & 84.4 \\
Não & 46 & 15.6 \\
\hline
\end{tabular}

Fonte: Autor do trabalho com base nos dados recolhidos no campo, em 2103

Factores determinantes do desempenho das múltiplas funções de agricultura desenvolvida pelas famílias rurais

Cazella, et al (2009) advogam como principais factores do desempenho das múltiplas funções de agricultura familiar, as dinâmicas territoriais e os projectos colectivos. São aspectos das dinâmicas territoriais os projectos colectivos, as iniciativas privadas, as iniciativas individuais dispersas ou fragmentadas e as políticas públicas.

As dinâmicas territoriais e os projectos colectivos dizem respeito, tal como sustentam Cazella et al (2009:60), aos arranjos dos actores sociais e/ou institucionais em tornos de objectivos e recursos compartilhados que intervêm sobre os territórios dados (projectos colectivos) e à tradução no espaço e no tempo, das repercussões económica, social, politica e ambiental das acções dos actores e das relações (alianças e conflitos) entre eles (dinâmicas territoriais).

\section{Projectos colectivos}

Neste conteúdo faz-se referência a alguns projectos colectivos que actuam na dinâmica do distrito de Chibuto, concretamente nos postos administrativos (PA's) observados, na sua relação com a agricultura praticada pelas famílias rurais. Constituem projectos colectivos, algumas associações dos agricultores, instituições públicas como o Conselho Municipal da Cidade de Chibuto (CMCC), o Instituto Nacional de Acção Social - Delegação de Chibuto (INAS) e os Serviços Distritais de Actividades Económicas de Chibuto (SDAEC).

SDAE (2012), refere que no ano 2012, o distrito de Chibuto dispunha de 39 associações agrícolas com 1924 membros dos quais 1323 eram mulheres e 632 homens. Para além das associações que correspondiam uma porção da extensão pública, o SDAE contava com 13 parceiros de cooperação com 18 técnicos e 04 empresas de fomento com 09 técnicos. 
Dados disponibilizados pelos agricultores ditam que, nos PA's em estudo existem associações e projectos agrários, como: Associação de Missão Malehice, Associação Lirhandzu, Associação Tsika-Ulolo, Associação Estender Mão, Associação Kusheula, Associação Mata Fome, Associação Txivirica, Projecto Comida pelo Trabalho, Auxilio Mundial, Projecto de Estrada Mbambane, entre outros.

A tabela 6 apresenta dados relativos à participação dos membros de AF's nos projectos colectivos como as associações. Tal como pode se notar, maior parte dos membros das famílias no distrito não fazem parte de nenhuma associação. Dos poucos, a maioria está integrada na Associação Tsika-Ulolo, localizada no Posto Administrativo de Malehice, cujo seu objectivo fundamental é do desenvolvimento comunitário através da promoção de agricultura e criação de frangos. Os efeitos de actuação da associação no PA, tal como referiu o presidente da mesma, refletem-se na produção e comercialização agrícola e pecuária, na protecção dos recursos hídricos e na ajuda à população nas suas actividades

\section{Iniciativas privadas}

As iniciativas privadas funcionam como vectores dinamizadores de territórios, dado que, no contexto da agricultura, elas permitem, através da venda dos produtos agrícolas, a obtenção do rendimento agrícola, o que possibilita a reprodução económica e social das famílias. Nesta lógica, existem em Chibuto, concretamente nos PA's observados, algumas organizações não-governamentais individuais e colectivas (propriedades privadas) que empregam um número considerável de camponeses, tais como as machambas do Ramtula Mussagy e a empresa agrícola dos Turcos, ambas localizadas no PA de Chaimite.

Para além das propriedades privadas, destacam-se as organizações privadas que mantém a cooperação com as instituições públicas, sobretudo com a SDAEC, como já se referiu anteriormente, e constituem alavancas para viabilizar o desenvolvimento agrícola do distrito e, consequentemente, o bem-estar social das famílias rurais. São algumas delas a Visão Mundial, Save The Children, Auxilio Mundial (World Relief), Samaritan e ATEDECO.

A visão Mundial no Distrito, concretamente em Malehice, tem dentre vários objectivos, a capacitação das famílias e comunidades em matéria de agro-negócios, como forma de garantir o bem-estar das crianças; a contribuição para a redução da 
desnutrição crónica entre as crianças e garantir a segurança alimentar; a garantia do acesso à água potável nas comunidades locais. Portanto, esta organização actua na esfera social como dinamizadora do desenvolvimento das famílias rurais do distrito.

Iniciativas individuais dispersas ou fragmentadas

As iniciativas individuais dispersas ou fragmentadas referem-se àquelas actividades exercidas sobre os territórios que não se apresentam enquadradas nos exercícios formais ou que não são conduzidas pelas políticas públicas ou movimentos sociais. Para esta análise configuraram-se iniciativas individuais dispersas ou fragmentadas, todas as outas actividades não formais exercidas fora do âmbito agrícola.

Como se pode notar no gráfico 3, poucas famílias têm desenvolvido outras actividades para além da agricultura e o gráfico ilustra as poucas desenvolvidas pelas famílias rurais do distrito destacando-se a mineira na Africa do Sul, a pesqueira, a construção de casas com material local e melhoradas, o comércio informal, a tecelagem de esteiras, entre outras.

\section{Políticas Públicas}

As políticas referidas nesta pesquisa são designadas por políticas territoriais, as que abrangem "toda e qualquer actividade estatal que implique, simultaneamente, uma dada concepção do espaço nacional, uma estratégia de intervenção ao nível da estrutura territorial e, por fim, mecanismos concretos que sejam capazes de viabilizar essas políticas" (COSTA, 1988:13).

Fazem parte das políticas territoriais, as políticas agrárias que no seu conteúdo devem reportar elementos fundamentais para o desenvolvimento da agricultura no meio rural. O gráfico 4 alude a principal fonte de crédito agrícola para as famílias camponesas do distrito de Chibuto, concretamente nos PA's em estudo, como um indicador de concretização dessas políticas. Portanto, muitas familias camponesas não têm acesso ao crédito agrário por parte do governo, salvo as que estão associadas, implicando que para sustentar a produção agrícola contam com a sua fonte própria. 
Tabela 6. Participação dos membros dos AF's nos projectos colectivos

\begin{tabular}{ccc}
\hline Características & Frequência & Percentagem \\
\hline $\begin{array}{c}\text { Algum membro da família } \\
\text { faz parte de uma associação }\end{array}$ & $(\mathrm{n}=299)$ & 100.0 \\
Sim & 45 & 15.1 \\
Não & 254 & 84.9 \\
& & \\
Nome de associação & $(\mathrm{n}=299)$ & 100.0 \\
Associação Tsika-Ulolo & 18 & 6.0 \\
Projecto comida pelo trabalho & 9 & 3.0 \\
Associação Kusheula & 3 & 1.0 \\
Ocupa ou já ocupou um & & 100.0 \\
cargo na associação & $(\mathrm{n}=299)$ & 2.0 \\
Sim & 6 & 98.0 \\
Não & 293 &
\end{tabular}

Fonte: Autor do trabalho com base nos dados recolhidos no campo, em 2103

Gráfico 3. Algumas iniciativas individuais

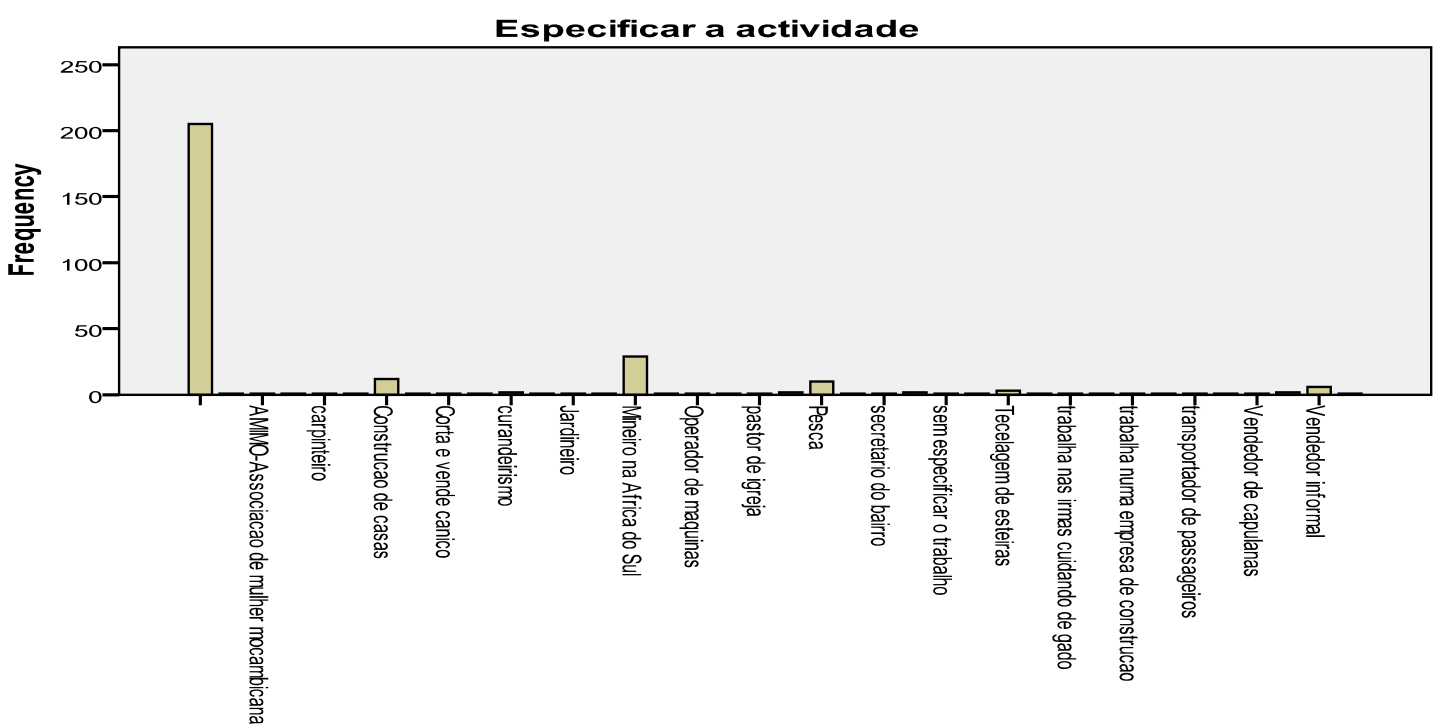

Fonte: Elaborado pelo Autor com base nos dados do campo, 2014

Gráfico 4. Fonte de crédito para actividade agrícola

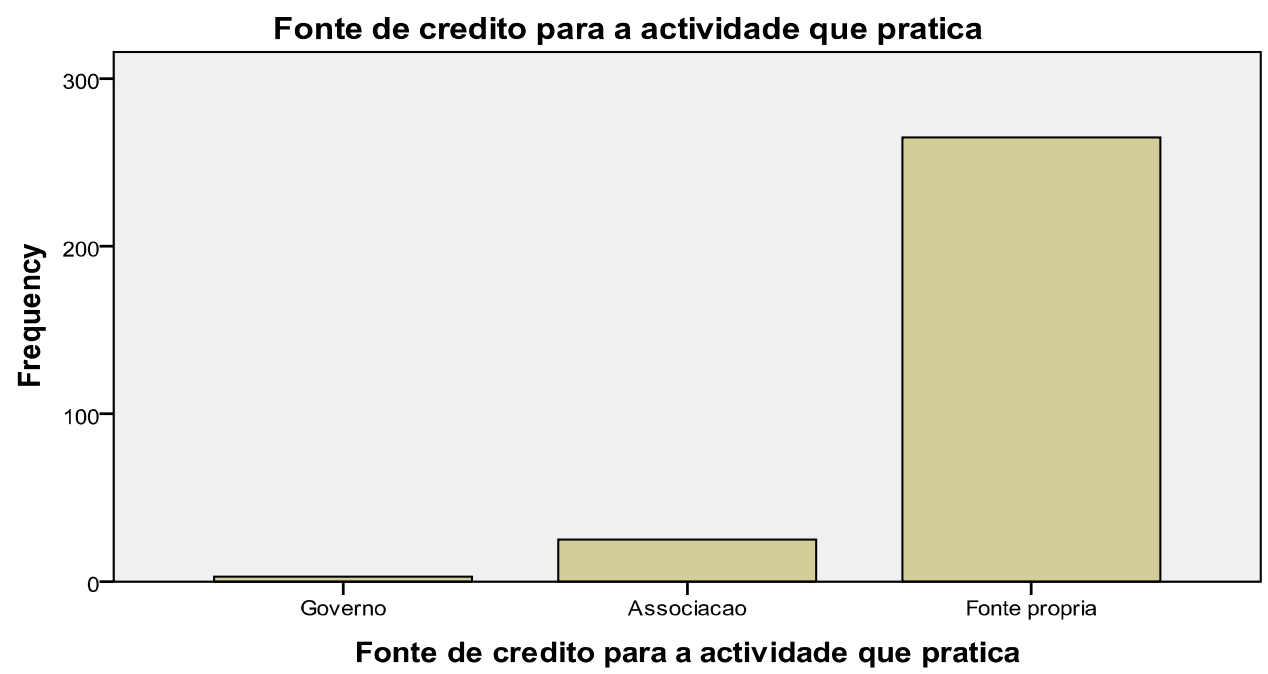

Fonte: Elaborado pelo Autor com base nos dados do campo, 2014 


\section{DISCUSSÃO}

Em função dos dados apresentados, pode-se afirmar que a agricultura praticada pelas famílias rurais do Distrito de Chibuto não desempenha significativamente o papel de reprodução socioeconómica das famílias rurais dado que não garante o emprego principalmente para os jovens e, pelo facto de ser uma actividade não assalariada, garante um rendimento familiar bastante reduzido que não permite a permanência, em muitos casos, dos jovens nas comunidades.

Sobre este facto, Chayanov (1981:133/34) diz que “(...) uma área muito vasto da vida económica (a maior parte da esfera de produção agrária) baseia-se, (...) numa forma (...) de unidade económica familiar não assalariada", o que torna não rentável em termos monetários. Pelo facto, muitos jovens deslocam-se das suas comunidades para os outros lugares a procura do emprego, e trata-se de um fenómeno que se verifica um pouco por toda a zona Sul de Moçambique e, de entre várias razões que o explicam, Mapengo (2011:70) destaca, no seu estudo sobre a migração rural-urbana na cidade de Maputo, a procura do emprego e a guerra.

Os resultados mostraram também que o distrito não consegue produzir uma quantidade suficiente para o autoconsumo, pese embora que o destino da produção é do consumo familiar, significando que a segurança alimentar não é suficientemente garantida. Esta situação tem contribuído, por sua vez, para o aumento de casos de desnutrição crónica. O Plano de Acção Multissectorial para a Redução da Desnutrição Crónica em Moçambique 2011-2014 (2020) (RM, 2010:5) citando MICS (2008) sustenta que $44 \%$ das crianças moçambicanas sofrem de desnutrição crónica ou baixa altura para a idade.

Outro aspecto da multifuncionalidade de agricultura é a manutenção do tecido social e cultural. No Distrito de Chibuto, este aspecto revela-se em níveis reduzidos dado que as famílias e as comunidades não conseguem manter, na sua plenitude, os seus hábitos e costumes. A pesquisas sobre o desenvolvimento da agricultura sob o capitalismo de Ferreira \& Mêsquita (2009:26) mostra a origem da contradição entre a agricultura camponesa e agricultura familiar, referindo-se que "ser camponês é ter uma identificação com a terra e por dinheiro nenhum vendê-la. Ser camponês é, recebendo influências de outras culturas, manter os seus costumes". Portanto, é um aspecto a ter em conta nas funções atribuídas à agricultura familiar. 
Igualmente, os dados analisados aludem que, embora seja difícil referir-se desta variável, a agricultura praticada pelas famílias rurais não agencia significativamente a função de preservação dos recursos naturais e da paisagem rural do distrito pois, poucas técnicas (modernas) se usam para a conservação do solo, poucos usavam agrotóxicos como preventores de acção danosa dos parasitas, e é notável também a predominância de desmatamento e/ou queimadas. A técnica mais usada pelos camponeses é de adubação orgânica recorrendo ao estrume e ao capim decomposto como fertilizantes. Mazoyer \& Roudart (2010) chamam à atenção da importância dos adubos, sobretudo orgânicos como os dejectos animais, o estrume e adubos verdes, na proporção às plantas de minerais nutritivos, aumentando, deste modo, a sua produção.

Sobre o desmatamento e/ou queimadas, Mazoyer \& Roudart (2010:130) afirmam que o desmatamento (no período neolítico como eles sugerem ter iniciado o desmatamento) geralmente traduziu-se por uma degradação de fertilidade, pelo aparecimento de processos erosivos mais ou menos graves conforme o biótopo, e uma mudança do clima capaz de levar até mesmo à desertificação, justificando-se pela exploração de madeira tropical e a expansão de plantações e áreas de criação.

O desempenho da agricultura familiar no distrito de Chibuto pode ser explicado pelas dinâmicas territoriais e projectos colectivos, das quais, os projectos colectivos presentes nos postos administrativos em referência revelam um papel reduzido no desempenho de múltiplas funções de agricultura no distrito visto que, embora os dados de SDAE apresentarem um número significativo de associações formais presentes, os membros das famílias integrantes dessas associações são bastante reduzidos. Nestas circunstâncias, os agricultores ficam limitados em termos de acesso às novas tecnologias agrárias, ao crédito agrícola, às informações acerca de políticas agrárias, a produtos alimentares, a insumos agrícolas, entre outros benefícios.

Buainain (2006), ao explicar a importância das associações dos agricultores, diz que o grau de organização e participação dos produtores familiares em organizações sociais, como cooperativas e associações de produtores, tem impacto directo sobre a capacidade de adopção de novas práticas, produção e eficiência do uso dos recursos. De um lado, a associação de interesses pode viabilizar o acesso à tecnologias e serviços que não estariam disponíveis para o produtor individual. Do outro lado, a organização geralmente resulta em mais e melhor informação, em amparo dos mecanismos colectivos de planeamento e em gestão de actividades. 
As iniciativas individuais dispersas ou fragmentadas reportam-se também influentes no desempenho das múltiplas funções de agricultura em virtude de garantir o emprego às famílias, embora não formal, o seu rendimento que permite a compra de alguns insumos agrícolas, a compra de produtos alimentares para a família, entre outros benefícios. São estas actividades que têm garantido a reprodução socioeconómica das famílias rurais do distrito, dado que a agricultura não se revela sustentável para elas, em termos de garantir a segurança alimentar e nutricional. Para sustentar a realidade observada, Mosca (2012) faz referência ao surgimento do comércio informal nas zonas rurais decorrente da destruição que a guerra (dos 16 anos) provocou para grande parte das infra-estruturas.

Mosca (2009) citado por Mosca (2012:33) "defende que as economias informais contribuem para a redução da pobreza gerando rendimentos e emprego a curto prazo, mas constituem um obstáculo ao desenvolvimento económico a longo prazo". Para além do comércio informal, a actividade mineira integra muitos jovens e adultos que emigram das suas comunidades à procura do emprego para sustentar as suas famílias garantindo a sua reprodução socioeconómica.

Os programas públicos como variável fundamental na explicação do desempenho de múltiplas funções de agricultura desenvolvida pelas famílias rurais, reportam uma influência negativa sobretudo, no acesso ao crédito agrícola por parte das famílias camponesas dado que estas não têm recebido crédito do governo, significando que não existem políticas públicas que, no concreto incentivam as famílias a produzirem através da disponibilidade do crédito agrícola. Essas famílias encontram solução nas suas iniciativas individuais, como se referiu anteriormente. Não obstante a existência de políticas de âmbito nacional que tem interferido na dinâmica do distrito, estas não temse reportado com convergência no seu campo de actuação.

Portanto, o facto de maior parte dos respondentes afirmarem que a fonte de crédito é própria revela que o governo, que devia ser responsável pela disponibilização do crédito agrícola aos camponeses, não se faz sentir, de tal forma que estes tornam-se sujeitos às regulações do mercado "sem condições de concorrerem com produtos que recebem auxílio proteccionista", tal como se referiu anteriormente ao citar Segrelles (2007) citado por Nunes \& Serrano (2009).

Deste modo, a noção de multifuncionalidade de agricultura como modelo a seguir deve ser tomada em consideração quando se pretende traçar políticas e estratégias de desenvolvimento rural sustentável do distrito de Chibuto. 


\section{Agradecimento}

O autor endereça os seus agradecimentos à Universidade Pedagógica, Delegação de Maxixe, por ter-lhe dispensado durante a recolha de dados no Distrito de Chibuto. Os agradecimentos vão também para as famílias camponesas dos Postos Administrativos de Malehice, Chibuto-Sede e Chaimite; para as Instituições como o SDAE, o CMCC e o INAS; para a Visão Mundial - Malehice; e para as Associação Tsika-Ulolo e outras, pela colaboração durante a recolha de dados.

\section{REFERÊNCIAS BIBLIOGRÁFICAS}

BUAINAIN, António Márcio. Agricultura Família, Agroecologia e Desenvolvimento Sustentável: Questões para Debate. $1^{\text {a }}$ Edição. Brasília. Editora IICA. 2006. [Online], obtido em repiica.iica.int/docs/B0417p/B0417p;

CAZELLA, Ademir. A, et al. (Org.). Agricultura Familiar: Multifuncionalidade e Agricultura Familiar no Brasil. Rio de Janeiro. Mauad X. 2009. [Online], obtido em http://wp.ufpel.edu.br/consagro/files/2011/08/CAZELLA-BONNAL-MALUFAgricultura-Familiar-Multifuncionalidade;

CHAYANOV, A. V. Sobre a Teoria dos Sistemas Económicos Não Capitalistas. In SILVA, J. Graziano da \& STOLEKE, V. Questão Agrária. SP, Brasiliense. 1981.

COMISSAL, Hortêncio P. Glossário de Ciências Agrarias. $1^{\mathrm{a}}$ Ed. Maputo. Alcance Editores. 2011.

COSTA, Wanderley M. da. O Estado e as Politicas Territoriais no Brasil. São Paulo. Contexto. 1988.

FERREIRA, Ana P. de M. \& MESQUITA, Helena A. de. $O$ Sentido do Desenvolvimento da Agricultura sob o Capitalismo: Paradigmas em Debate. Revista Pegada, v. 10, n. 1. P. 15-28. 2009. [Online], obtido em http://revista.fct.unesp.br/index.php/pegada/article/viewFile/1667/1603.

INE (Ed.). III Recenseamento Geral da População e Habitação, 2007. Resultados definitivos da Província de Gaza. Maputo. 2010.

MAPENGO, Manuel. Migração Rural-Urbana e Crescimento Populacional da Cidade de Maputo. Edição PubliFix. Maputo-Moçambique. Centro de Analises de Politicas, Faculdade de Letras e Ciências Sociais, Universidade Eduardo Mondlane. 2011.

MAZOYER, Marcel \& ROUDART, Laurence. História das Agriculturas no Mundo: Do Neolítico à Crise Contemporânea. São Paulo. Editora UNESP. 2010. [Online], obtido em

http://w3.ufsm.br/gpet/files/Historia\%20das\%20agriculturas\%20no\%20mundo\%20$\%$ 20Mazoyer\%20e\%20Roudart.pdf.

MESQUITA, Paulo E. de. Multifuncionalidade e Preocupações Não-Comerciais: Implicações para as Negociações Agrícolas na OMC. Brasília. Instituto Rio Branco e Funag. $2005 . \quad$ [Online], obtido em http://www.funag.gov.br/biblioteca/dmdocuments/0320.pdf. 
MOSCA, João (coord.). Contributos para o Debate da Agricultura $e$ do Desenvolvimento Rural. Maputo-Moçambique. Escolar Editora. 2012.

MOSCA, João. Politicas Agrarias de (em) Moçambique (1975-2009). MaputoMoçambique. Escolar Editora. 2011.

MULENGA, Alberto. Introdução à Estatística. Maputo. 2010.

NUNES, João O. R. \& SERRANO, José A. S. Análise Agrária da Multifuncionalidade da Terra na Província de Alicante - Espanha. Revista Nera - Ano 12, N. 14, P. 18066755, Janeiro/Junho 2009 - ISSN. [Online], obtido em rua.ua.es/dspace/bitstream/10045/12661/3/7_nunes.pdf.

SDAE. Relatório de Actividades para o Conselho Coordenador da DPA. Chibuto, Outubro de 2012.

WANDERLEY, Maria de N. B. Agricultura Familiar e Campesinato: Rupturas e Continuidades. Estudos Sociedade e Agricultura. Rio de Janeiro, 21. 42-61. 2003. [Online], obtido em http://r1.ufrrj.br/esa/V2/ojs/index.php/esa/article/viewFile/238/234. 